\title{
REFLECTIONS ON THE PASSING OF PROF BONGANI MAYOSI: UNIVERSITIES AND THE BURDEN OF HISTORY
}

\author{
L. Thaver* \\ Department of Sociology and Anthropology \\ e-mail: Ithaver@uwc.ac.za
}

\section{B. Thaver*}

Institute for Postschool Studies, Higher Education, Faculty of Education

e-mail: bthaver@uwc.ac.za

*University of the Western Cape

Bellville, Cape Town, South Africa

Our heartfelt condolences to the family of Prof Bongani Mayosi. We begin by acknowledging that the condition of depression stalks societies, it silently chips away at the soul and identity of an individual. And, when tragedy strikes in the form of suicide, we desperately formulate questions in the hope that there will be clear answers. We have been witness to this confounding emotional process in our family. Notwithstanding, we continue to keep hope alive that advances in the social and natural sciences will walk us through the dense thicket of the vortex of our emotions. After all, it is the latter that is brought to bear on the everyday practices of our professional lives. Given that the psychological profile of an individual is layered onto the professional-workplace and since, Prof Mayosi's tragedy is within the context of the university environment, we wish to reflect on the environment in which as academics we find ourselves in the current context.

Our first reflection notes the pre-eminence Prof Mayosi has come to hold in our society, as a result of the level he had achieved in his field, which was one of the highest order: a doctorate from Oxford University, an A-rating from the National Research Foundation and the bestowal of the South African President's honour, the Order of Mapungubwe. This is testimony to an individual of immense character, strength, courage, conviction and discipline, for he pushed against the historical tide of coloniality and apartheid, and who in the face of such adversity emerged at the top of his exacting profession of choice.

In regard to the classic idea of the Western modern university as far as it involves the unity of research and teaching in the pursuit of knowledge, Prof Mayosi distinguished himself. Firstly, he achieved world leadership in research in his field of medical specialisation in 
Rheumatic heart disease made manifest in his leadership of the Global Rheumatic Heart Disease Registry (the REMEDY). In this respect, he was true to the scientific ideal of the university, and moreover, in blazing new trails in how medical science understood infectious diseases. It had both epistemic and social implications. Firstly, inasmuch as he introduced a division for infectious diseases which resulted in the establishment of Institute of Infectious Disease and Molecular Medicine, it is an epistemic innovation. Secondly, in relation to the social implicate he redressed the misalignment of the Department of Medicine at the University of Cape Town and Groot Schuur Hospital, by noting that "it was geared to treat the diseases of some 5 million South Africans, not all 55 million South Africans" (Mayosi 2016). For him the department “... had to become relevant to 55 million South Africans" (Mayosi 2016) which as such amounted to a paradigmatic shift inasmuch as it reorients medical science at the University of Cape Town from the study of the "diseases of the rich" to those of the "diseases of the poor". The net effect in short is an example, par excellence of the decolonisation of knowledge in Medical Science.

Given these outstanding intellectual achievements by any measure, beckons the burden of leadership at two levels. The first is in his own scientific field, where he was appointed to visionary leadership positions, nationally and internationally. The second, was at the level of institutional (university) leadership, a call Prof Mayosi accepted with humility in his roles as head of the Department of Medicine at UCT and Groote Schuur Hospital, and then as Dean of the Faculty of Health Sciences. The exemplary achievement of becoming Dean of the Faculty of Health Sciences belies the historical weight and volume of an institution that is represented in the structure in which the Deanery is located. Our reflection (which includes a reading of public documents) is that inasmuch as there were attempts at reforming the Higher Education system (post 1997) through social policy interventions, these were insufficient to take on the historical weight of the legacy that has come to define and radiate throughout the university sector. In the main, the internal academic structures and cultures of the university which were regulated over time by Western norms, values, belief and practices (cultures) remained intact. Thus, despite the shifts in certain symbolic gestures (such as name changes of buildings), it is noted that the actual social and power relations around the knowledge (academic) project remain unchanged. We emphasise here, that the conservative and so-called universal (read as Western) character of intellectual thought and practices are inured by the notion of institutional memory. What this means, is that certain practices have become naturalised over time and hence considered beyond question, by the status quo.

It turns out that this historical structure has a baggage that has been channelled, divined and selectively deposited upon Prof Mayosi. This fundamentally is a retreat of social accountability that must be placed squarely at the feet of the institution in all its structures, its 
symbolism and everything it comes to represent. Its fundamental fault and flaw is this. It placed the burden of history on Prof Mayosi and offered him inadequate support. He had to carry the burden of history that was not of his making, he had to interface the very forces that challenged the status quo which, he, as his scientific work suggests, was inclined to support. Thus, in the position of Dean, he was in a contradictory place with regard to the student protests. The real tragedy is the failure of the university to accept its own burden of history and this is the pathos which carries the name of Prof Bongani Mayosi.

Noting the above, the question that begs is: how toxic does an institution's culture have to be to drive a man of such calibre to the point of despair. This is the elephant in the room, i.e. the toxic cultures that pervade our institutions and are responsible for the human, social and cultural fall-out for which we continue to pay for in social alienation. From our vantage point of having been at the coalface of teaching and research in the university site, since the dawn of democracy, we have been struck in our research endeavours by the structural and institutional dynamics associated with university working life framed by transformational processes. What is noteworthy, is the phenomenon of instability which has catastrophically become more concentrated over the last two to three years.

The liberal humanist idea of the university, while it has many virtues of exploring the dimensions of being, in a holistic manner, it sadly falls short on the idea that society is predicated on the individual and inasmuch as it sees the individual as the prime agent, it has held Prof Mayosi to account for the history, yet, not one of his own making.

Given the complexity in which we contextualised the tragedy of Prof Mayosi could we ask whether Prof Mayosi was sacrificed at the rub of the tension betwixt autonomy, accountability and representivity. Furthermore, could one ask whether Prof Mayosi was the intermediary, insofar as he was expected to represent and defend the university and its burden of history in the face of the broader sweep of social transformation with its impatient timeline.

So, there are questions: What does the individual do, when the weight of the colonial history descends on the individual? How do we understand institutional repression in the subtle ways that it defines and confines individual autonomy, in the specific ways that Prof Mayosi was confined, repressed and contained? Moreover, we similarly ask, what do we make of what has come to be represented as a discernable strategy in which historically white institutions instrumentally use black academics and members of staff as fronts and bulwarks and intermediaries when engaging with students? It is this untenable position that the university put Prof Mayosi in that is fundamentally responsible for heightening the contradictions that he faced, as one committed to social transformation, whilst at the same time confronted by the slow pace and even resistance of the institution to transform its character both epistemologically 
and culturally.

In conclusion what we are drawing attention to is that Prof Mayosi is symptomatic of the university which is severely wanting in terms of the reflexivity required to bring the intellectual resources of critique to bear upon the university itself. And thus, to provide a re-imagining to social and epistemic transformation, in ways that establish the deep connective between university and society which blurs the divide between town and gown. Finally, what we glean from this rather unfortunate tragedy is the reluctance, or rather the recusal of the university from engaging the burden of its history. Moreover, that in taking refuge in notions such as institutional and academic autonomy it has amounted to a vain attempt to pardon the academy from its historical burden and attendant human costs.

We have sacrificed a role model. It is incumbent upon us now to make public the contribution of Prof Mayosi to Medical Science and propose that Plaques be placed at each of Cardiology Units to memorialise Prof Mayosi.

\section{REFERENCES}

Mayosi, B. 2016. Fast tracking professors is key to transformation. http://www.health.uct.ac.za/ news/fast-tracking-professors-key-transformation 